\title{
Correlation Analysis between Grain Color and Cyanidin-3-glucoside Content of Rice Grain in Segregate Population
}

\author{
Tae-Ho Ham ${ }^{1}$, Soon Wook Kwon ${ }^{2}$, Su-Noh Ryu ${ }^{1}$, Hee-Jong Koh ${ }^{3 *}$ \\ ${ }^{1}$ Dept. of Agricultural Science, Korea National Open University, Seoul 110-791, Korea \\ ${ }^{2}$ Dept. of Plant Bioscience, Pusan National University, Miryang 627-706, Korea \\ ${ }^{3}$ Dept. of Plant Science, Seoul National University, Seoul 151-742, Korea
}

\begin{abstract}
This study examined the genetic variation of cyanidin 3-glucoside (C3G) contents in blackish-purple rice. $\mathrm{F}_{2}$ populations were established from crosses between blackish purple rice and normal white rice. The blackish rice cultivars used were Jilinheimi, Heidao38, LK1A-2-12-1-1, Heugjinju, and No2, and the common white rice cultivars used were Hwachung super giant embryo and Heugbal. The purple pericarp color is known to be controlled by a set of dominant alleles, $\operatorname{Pb}(\operatorname{Prp}-b)$ and $\operatorname{Pp}(\operatorname{Prp}-a)$. In this study, the segregation of the black purple:brown:white pericarp in the $F_{2}$ population was 9:3:4, demonstrating that the purple pericarp color was controlled by two dominant complementary genes. The $\mathrm{F}_{2}$ distribution of $\mathrm{C} 3 \mathrm{G}$ showed continuous variation, with a tendency toward a lower level in all the crosses. However, some $F_{2}$ crosses, such as Jilinheimi/Heidao38 and Jilinheimi/LK1A-2-12-1-1, showed transgressive segregation of the $\mathrm{C} 3 \mathrm{G}$ content. $\mathrm{C} 3 \mathrm{G}$ content of Jilinheimi linked on $84 \%$ level in $\mathrm{C} 3 \mathrm{G}$ content of $\mathrm{F}_{2}$ population between Jilinheimi/Heidao38, and 41.3\% level in Jilinheimi/LK1A-2-12-1-1. The results of the color difference meter and C3G content analysed by HPLC revealed highly significant correlations between the seed coat color of the colored rice germplasm and that of the segregated populations. There was a significant positive correlation between the C3G content with $L^{*}$ (lightness) and $b^{*}$ (yellowness). The $a^{*}$ (redness) was different in each cross, but there was a significant positive correlation between the C3G content with $L^{*}$ and $b^{*}$.
\end{abstract}

Keywords Colored rice, Anthocyanin, C3G (cyanidin 3-glucoside), Color difference meter

\section{INTRODUCTION}

Annual rice consumption per person has dropped from $135.6 \mathrm{~kg} / \mathrm{capita} /$ year in 1979 to $69.0 \mathrm{~kg} /$ capita/year in 2013. In conjunction with the drop in consumption, customers' requirements have diversified, with consumers demanding functional and healthful, as well as tasty rice. Various qualities of rice, such as its physical appearance, cooking properties, eating properties, and, more recently, nutritional value, affect consumers' acceptance of the product and the product's market value. Therefore, improving the rice varieties according to consumers needs were main objectives of rice breeding activities (Fitzgerald et al. 2009). The potential of colored rice as a functional food with health benefits (Choi et al. 1994; Kang et al. 1996), as well as its potential as a natural pigment (Choi et al. 1996) and in cosmetics, has been studied.

In the past, the rice bran and germ produced during the milling process was disposed of, without utilizing these by-products of rice production. However, following research showing that rice bran includes a variety of useful components, such as oryzanol, phytic acid, ferulic acid, arabinoxylan, and arabinogalactan, its potential as a new functional ingredient has received increased attention. In particular, pigmented rice bran, rather than the bran of normal rice, is attracting attention because of its high antioxidant activity (Cho et al. 1996; Osawa 1995).

Genetic fortification of rice grain with functional compounds for human health is one of the major objectives in breeding programs for better and diversified grain quality in rice. Colored rice contains a variety of natural colors, ranging from dark purple to maroon and green (Park

Received May 15, 2015; Revised Jun 26, 2015; Accepted Jun 28, 2015; Published June 30, 2015

*Corresponding author Hee-Jong Koh, heejkoh@snu.ac.kr, Tel: +82-2-880-4541, Fax: +82-2-873-2056 
et al. 1998). Black and dark purple rice are known to contain a large amount of anthocyanin pigments, whereas red and maroon rice contain tannins. The anthocyanin pigment of black-purple rice contains a large amount of cyanidin3-glucoside $(\mathrm{C} 3 \mathrm{G})$, up to $80 \%$, as well as peonidin-3glucoside (P3G), malvidin, pelargonidin, and selphinidin (Reddy et al. 1994; Cho et al. 1996; Ryu et al. 1998).

$\mathrm{C} 3 \mathrm{G}$ is the key component of anthocyanin, which is responsible for the color pigmentation in black-purple rice, and is known to have antioxidative potential (Reddy et al. 1995). A Korean blackish-purple rice cultivar, Heugjinju, was reported to contain $470 \mathrm{mg} / 100 \mathrm{~g}$ of C3G, which is the highest concentration among cultivated rice in Korea (Kim et al. 2000). The grain color of black-purple rice is known to be controlled by the complementary action of two dominant genes, $P b(\operatorname{Pr} p-b)$ and $P p(\operatorname{Pr} p-a)$, located on chromosome 4 and 1, respectively (Hsieh \& Chang 1964; Yoshimura et al. 1997). The other grain color red also has complementary gene as $R c$ and $R d$ (Kinoshita 1984; Nagao \& Takahashi 1956).

This study was carried out to investigate the inheritance of the concentration of $\mathrm{C} 3 \mathrm{G}$ in segregate population and to explore the relationship between the intensity of pigmentation and the concentration of $\mathrm{C} 3 \mathrm{G}$.

\section{MATERIALS AND METHODS}

\section{Plant materials}

Five black-purple rice varieties, Jilinheimi, Heugjinju, Heidao38, No2, and LK1A-2-12-1-1, and two white rice varieties, Hwacheong super giant embryo and Heugbal, were used as parents of four populations. We performed two crosses each the black-purple variety/black-purple variety and black-purple variety/white variety. The blackpurple/black-purple crosses were Jilinheimi/Heidao38 and Jilinheimi/LK1A-2-12-1-1, and the black-purple/white crosses were Heugjinju/Hwacheong-ges and No2/Heugbal.

The colored rices and white rices were crossed in a greenhouse experiment in the summer and subsequent generations were advanced in a greenhouse in the winter. The $F_{2}$ population was sown and transplanted in the central region of Korea. In the $F_{2}$ population, the plants were harvested one by one, and $\mathrm{F}_{3}$ seeds were selected from 150 plants. In the analyzed of the $F_{2}$ segregation ratio, unhulled seeds of $\mathrm{F}_{3}$ were used, counted black-purple, red-brown and white seeds by visual, separately.

\section{Phenotypic traits}

Color measurements were expressed as tristimulus parameters $\left(L^{*}, a^{*}\right.$, and $\left.b^{*}\right)$ with a color difference meter (Chroma meter CR-200, Minolta, Japan). $L^{*}$ indicate lightness $(100=$ white, and $0=$ black $) \cdot a^{*}$ indicates rednessgreenness (positive $=$ red, and negative $=$ green), and $b^{*}$ indicates yellowness-blueness (positive $=$ yellow, and negative $=$ blue) .

\section{Extraction and detection of C3G}

The $\mathrm{C} 3 \mathrm{G}$ pigment from $2 \mathrm{~g}$ of brown rice was extracted and pulverized with $0.1 \%$ Trifluoroacetic acid (TFA) and $20 \mathrm{ml}$ of $95 \%$ ethanol solvent, three times every $4 \mathrm{~h}$ (Kwon et al. 2011). The extracted solution was filtered with filter paper (Whatman No.2) and concentrated under reduced pressure. The extracted solution was filled up with $2 \mathrm{ml}$ to HPLC analysis. C3G in anthocyanin extracted from the seed coat was analyzed with HPLC (waters 501 pump, millipore gradient controller, waters $480 \mathrm{UV}$-V is detector). An ODS-5 column $(4.6 \mathrm{~mm} \times 250 \mathrm{~mm}$, Nomura Chemical Co., Japan) was used, and detect wavelength was $530 \mathrm{~nm}$. The mobile phase was $0.1 \%$ TFA in water, the linear gradient was $0.1 \%$ in acetonitrile, and the flow rate was 1.0 $\mathrm{ml} / \mathrm{min}$

\section{RESULTS}

The segregation ratio of black:brown:white in the $F_{2}$ populations of crosses between the black and white rice was 9:3:4, in accordance with previous reports (Table 1). The segregation ratio differed in the $\mathrm{F}_{2}$ population crosses between the black rice, there were all black. These results indicate that two dominant complementary genes control the color pigmentation in the black-purple pericarp and that the pericarps of Jilinheimi, Heidao38 and LK1A-2-12-1-1 possess the same genes for color pigmentation. However, the depth of pigmentation varied continuously within the 
Table 1 Segregation of grain pericarp color in $F_{1}$ and $F_{2}$ of four crosses, Jilinheigmi/Heidao38, Jilinheimi/LK1A-2-12-1-1, Heugjiju/Hwancheong-ges, and No2/Heugbal.

\begin{tabular}{|c|c|c|c|c|c|c|c|}
\hline \multirow[b]{2}{*}{ Parents and crosses } & \multirow[b]{2}{*}{ Generation } & \multicolumn{4}{|c|}{ Pericarp color of grain } & \multirow{2}{*}{$\begin{array}{c}X^{2} \\
(9: 3: 4)\end{array}$} & \multirow[b]{2}{*}{$p$-value } \\
\hline & & $\begin{array}{c}\text { Blackish } \\
\text { purple }\end{array}$ & $\begin{array}{c}\text { Dark } \\
\text { brown }\end{array}$ & White & Total & & \\
\hline Jilinheimi & Parent & 5 & & & 5 & & \\
\hline Heidao38 & $"$ & 5 & & & 5 & & \\
\hline Heugjinju & $"$ & 5 & & & 5 & & \\
\hline No2 & $"$ & 5 & & & 5 & & \\
\hline LK1A-2-12-1-1 & $"$ & 5 & & & 5 & & \\
\hline Hwacheong-ges & $"$ & & & 5 & 5 & & \\
\hline Heugbal & $"$ & & & 5 & 5 & & \\
\hline \multirow{2}{*}{ Jilinheimi/Heidao38 } & $\mathrm{F}_{1}$ & All & & & 4 & & \\
\hline & $\mathrm{F}_{2}$ & All & & & 150 & & \\
\hline \multirow{2}{*}{ Jilinheimi/LK1A-2-12-1-1 } & $\mathrm{F}_{1}$ & All & & & - & & \\
\hline & $\mathrm{F}_{2}$ & All & & & 150 & & \\
\hline \multirow{2}{*}{ Heugjinju/Hwacheong-ges } & $\mathrm{F}_{1}$ & All & & & 3 & & \\
\hline & $\mathrm{F}_{2}$ & 89 & 29 & 32 & 150 & 0.87 & $0.75-0.5$ \\
\hline \multirow{2}{*}{ No2/Heugbal } & $\mathrm{F}_{1}$ & All & & & - & & \\
\hline & $\mathrm{F}_{2}$ & 87 & 34 & 39 & 150 & 2.14 & $0.5-0.25$ \\
\hline
\end{tabular}

Table 2. Correlation coefficients of evaluation methods of the seed coat color in $F_{2}$ seeds derived from a cross between Jilinheimi/Heidao38 and Jilinheimi/LK1A- 2-12-1-1.

\begin{tabular}{cccccc}
\hline \hline \multicolumn{2}{c}{ Jilinheimi/Heidao38 } & $\mathrm{X} 1$ & $\mathrm{X} 2$ & $\mathrm{X} 3$ & $\mathrm{X} 4$ \\
\hline Color & $L^{*}(\mathrm{X} 1)$ & & $0.442^{* * *}$ & $0.582^{* * *}$ & $-0.553^{* * *}$ \\
Difference & $a^{*}(\mathrm{X} 2)$ & & $0.373^{* * *}$ & $-0.332^{* * *}$ \\
Meter & $b^{*}(\mathrm{X} 3)$ & & & $-0.653^{* * *}$ \\
$\mathrm{C} 3 \mathrm{G}(\mathrm{X} 4)$ & & & & $\mathrm{X} 3$ & \\
\hline \hline \multicolumn{2}{c}{ Jilinheimi/LK1A-2-12-1-1 } & $\mathrm{X} 1$ & $\mathrm{X} 2$ & $0.756^{* * *}$ & $-0.697^{* * *}$ \\
\hline Color & $L^{*}(\mathrm{X} 1)$ & & $0.202^{* *}$ & 0.139 & -0.097 \\
Difference & $a^{*}(\mathrm{X} 2)$ & & & $-0.677^{* * *}$ \\
Meter & $b^{*}(\mathrm{X} 3)$ & & & \\
C3G $(\mathrm{X} 4)$ & & & & & \\
\hline
\end{tabular}

$L^{*}$ : lightness, $a^{*}$ : redness, $b^{*}$ : yellowness ${ }^{* *}, * * *$ : significant at the $1 \%$ and $0.1 \%$ level, respectively

color classes, as measured by a color difference meter, implying that other genes might also be involved in the color expression (Fig 1). The $\mathrm{C} 3 \mathrm{G}$ concentration of the brown rice exhibited continuous variations, with a tendency toward a lower value in all the $\mathrm{F}_{2}$ populations (Fig. 2). $\mathrm{C} 3 \mathrm{G}$ concentration varied widely, depending on the crosses and also found varying more or less transgressants. The variation in the $\mathrm{C} 3 \mathrm{G}$ concentration in $\mathrm{F}_{2}$ crosses did not correspond with that of color pigmentation. However, there were significant correlations between the $\mathrm{C} 3 \mathrm{G}$ concentration and $L^{*}$ (lightness) and $b^{*}$ (yellowness) values (Table 2).

\section{Genetic segregation of grain color}

Regardless of the combination, all the $F_{1}$ seeds were black, suggesting that a dominant gene affects the grain color. The $\mathrm{F}_{2}$ seed grain color in the black/black combination, 
Jilinheimi/Heidao38 and Jilinheimi/LK1A-2-12-1-1, was blackish, demonstrating that the parent of the black/black crosses had the same genes for black grain color.

The results of an $\chi 2$ analysis of the segregation of the grain color in the $\mathrm{F}_{2}$ population of the black/white crosses, Heugjinju/Hwacheong-ges and No2/Heugbal, was 9:3:4 (Table 1), indicating that Heugjinju and No2 has two genes associated with grain color and that these are complementary.



\section{Segregation and heritability of C3G content}

The $F_{1}$ and $F_{2}$ seeds of the black/black crosses were all black-purple, but the seed grain color of the $\mathrm{F}_{3}$ seeds from the $F_{2}$ segregated generation showed a continuous variation, as shown in Figure 1. A colorimeter revealed that the shape of the $\mathrm{C} 3 \mathrm{G}$ content in the $\mathrm{F}_{2}$ population from a combination of the black/black crosses was similar. As expected, transgressive segregation occurred in the Jilinheimi/Heidao38 and Jilinheimi/LK1A-2-12-1-1 crosses (Fig. 2).



Fig. 1. Frequency distribution of color value $a^{*}$ and $b^{*}$ using a color difference meter in the $\mathrm{F}_{2}$ population of Jilinheimi/Heidao38 (leaf) and Jilinheimi/LK1A-2-12-1-1 (right).
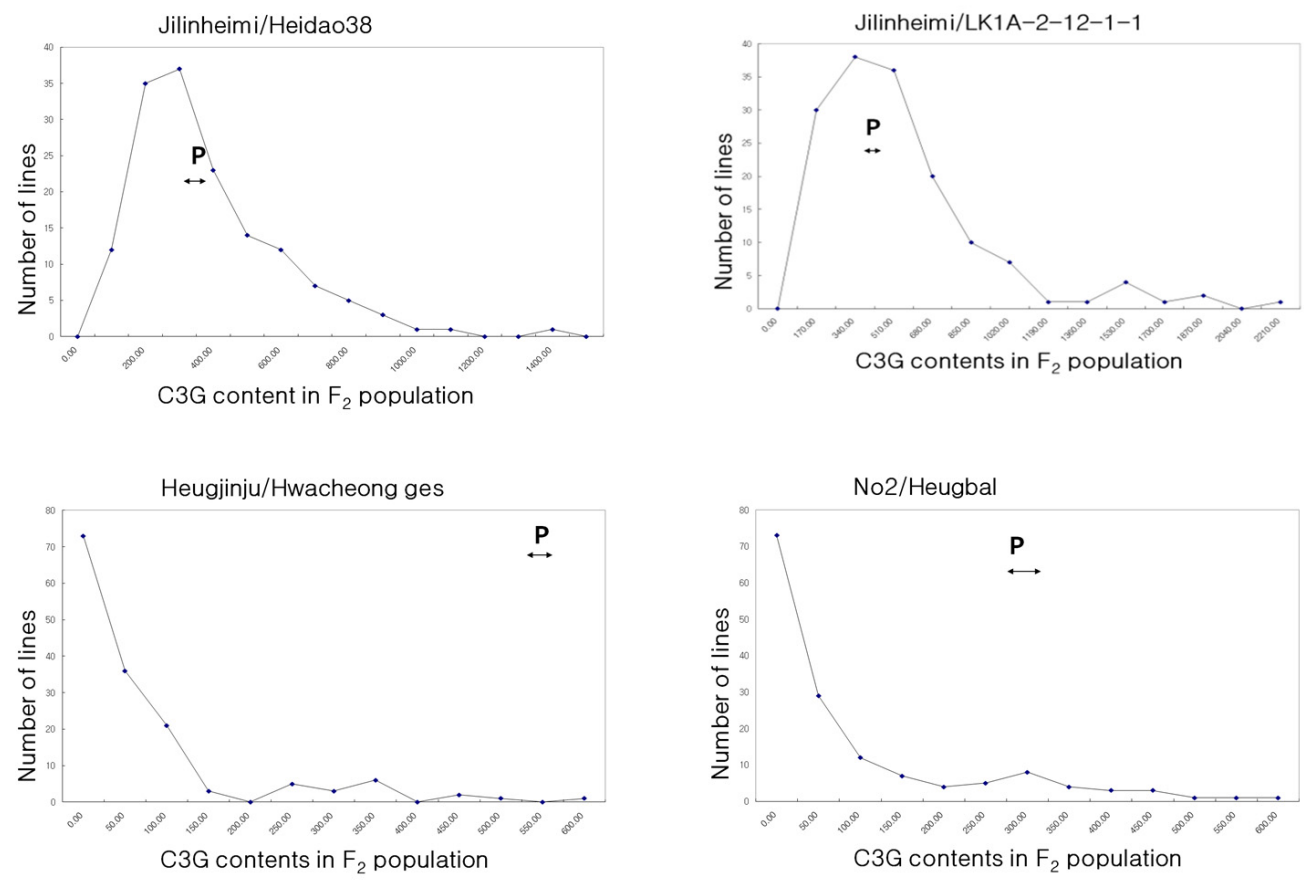

Fig. 2. Variation in the $\mathrm{C} 3 \mathrm{G}$ content $\left(\mathrm{mg} / 100 \mathrm{~g}\right.$ brown rice) of rice grain in $\mathrm{F}_{2}$ of four crosses/populations $P$ indicates the $\mathrm{C} 3 \mathrm{G}$ variation of the colored parents in the crosses. 


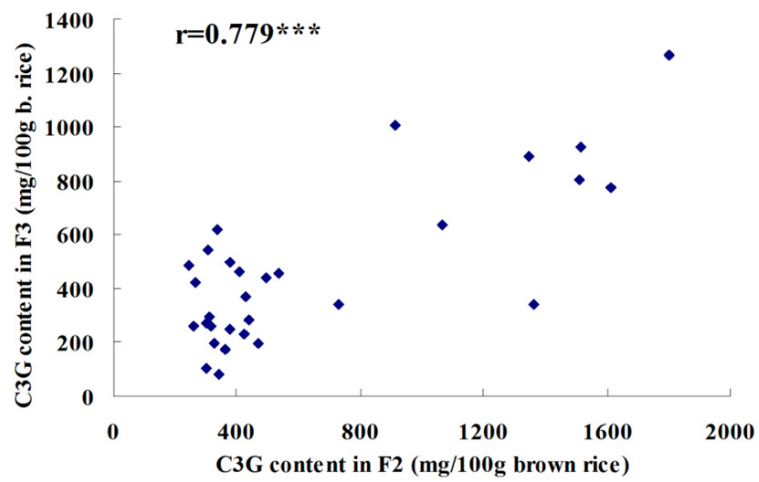

Fig. 3. $\mathrm{C} 3 \mathrm{G}$ concentration correlation between $\mathrm{F}_{2}$ plants and derived $\mathrm{F}_{3}$ lines. The standardized heritability estimate based on parent-offspring regression is the same as the correlation coefficient between generations.

\section{Correlations between colorimeter score and C3G content}

The $\mathrm{C} 3 \mathrm{G}$ content showed a significant negative correlation with $L^{*}$ (lightness) and $b^{*}$ (yellowness), but different aspect showed with $a^{*}$ (redness) by each combination (Table 2). In the Jilinheimi/Heidao38 combination, the lightness, redness, and yellowness had a highly significant negative correlation with the $\mathrm{C} 3 \mathrm{G}$ content. The colorimeter values revealed a highly significant positive correlation with each $L^{*}$ (lightness), $a^{*}$ (redness), and $b^{*}$ (yellowness) in theses crosses. In the Jilinheimi/LK1A-2-12-1-1 combination, the $\mathrm{C} 3 \mathrm{G}$ content had a significant negative correlation with $L^{*}$ (lightness) and $b^{*}$ (yellowness) but not with $a^{*}$ (redness). The colorimeter values correlation in $L^{*}$ (lightness) with $b^{*}$ (yellowness) and with $a^{*}$ (redness) were highly positive correlation, but negative correlation in $a^{*}$ (redness) with $b^{*}$ (yellowness). The correlation of the C3G content with $L^{*}$ (lightness) and $a^{*}$ (redness) differed, depending on the mating parents.

In particular, the separation aspects of the $a * / b^{*}$ was similar to the separation of the $\mathrm{C} 3 \mathrm{G}$ content, which is thought to be due to $a^{*} / b^{*}$ values representing the anthocyanin content (Fig 1 and Fig 2).

\section{DISCUSSION}

The potential of rice as a functional food has attracted attention in recent years, with research focusing, in particular, on dark purple rice. Since the early 1990s, dark purple crop varieties have been introduced from China.
Heugjinju (Moon et al. 1998) and Heugnam (Ha et al. 1998) has developed at rural development administration (RDA), but the yield of these varieties has remained at $70 \%$ as compared to that of normal varieties (Jung 2000).

The aim of the present study was to obtain basic data on color of pericarp using some pigmented rice varieties and to investigate the genetic underpinning selection for a high $\mathrm{C} 3 \mathrm{G}$ content. The $\mathrm{C} 3 \mathrm{G}$ content of some lines in the $\mathrm{F}_{2}$ population was considerably higher or lower than that of the parents. This phenomenon is referred to as transgressive segregation. Transgressive segregation for quantitative traits is very common, but the genetic basis is largely unknown (Liang et al. 2009). Transgressive segregation is a quantitative trait, and the $\mathrm{C} 3 \mathrm{G}$ content is controlled by a large number of genes. The Jilinheimi/Heidao38 and Jilinheimi/LK1A-2-12-1-1 combinations showed marked separation transcendence. The objects are separated beyond seems to be due to the cumulative effect or interaction effect of the gene to promote $\mathrm{C} 3 \mathrm{G}$ content thought to be useful in the selective breeding. The action of complementary genes may be the primary cause of transgression, although overdominance and epistasis also contribute (Rieseberg et al. 1999). In the present study, standardized heritability of the $\mathrm{C} 3 \mathrm{G}$ concentration estimated through selected $\mathrm{F}_{2}$ and $\mathrm{F}_{3}$ experiments was significantly high. These are suggest that selection for the $\mathrm{C} 3 \mathrm{G}$ concentration in early generations would be effective.

Studies have suggested that the genetic systems conferring color pigmentation and the $\mathrm{C} 3 \mathrm{G}$ content might not be the same but inter-related in a specific pathway 
associated with anthocyanin metabolism. This study can be partly explained by the fact that significant variations exist in the concentration of $\mathrm{C} 3 \mathrm{G}$, even among black-purple rice varieties (Park et al. 1998; Ryu et al. 1998). The results of $\chi 2$ analysis of the segregation of $\mathrm{F}_{2}$ population's grain color in black/white crosses, Heugjinju/Hwacheong-ges and No2/Heugbal was $9: 3: 4$. Jung et al. (2000) and Park et al. (2000) reported the same segregation ratio in Heugjinju/ IR701078-AC3(white) crosses and Hyangmi (white)/ Heugjinju crosses. Shen et al. (2009) reported that the color parameters of rice grain were positively correlated with the total phenolic content, flavonoid content, and antioxidant capacity among a wide collection of rice germplasms, including white, red and black rice, but that the correlations among the white rice accessions were rather weak. Jung et al. (2000) reported that the $\mathrm{C} 3 \mathrm{G}$ content of an $\mathrm{F}_{2}$ population had a highly significant negative correlation with colorimeter $a^{*}$ (redness) with $b^{*}$ (yellowness).

To shed light on the mechanism underlying transgression, it will be necessary to examine the interaction and activity of the dominant allele on heterozygote (Dooner et al. 1991). It will also be necessary to investigate the composition and quantitative differences in anthocyanin in the tissues of other plants, such as corn, snapdragon, and petunia, to shed light on the interaction between the structure and function of regulatory genes involved in the biosynthesis of anthocyanins.

\section{ACKNOWLEDGMENTS}

Financial support in the form of a grant for this work was provided by the Next-Generation BioGreen21 Program (PJ01108902), Rural Development Administration, Republic of Korea.

\section{REFERENCES}

Cho MH, YS Paik, HH Yoon, TR Hahn. 1996. Chemical structure of the major color component from a Korean pigmented rice variety. Agri. Chem. Biotech. 39: 304-308.

Choi, SW, WW Kang, T Osawa. 1994. Isolation and identification of anthocyanin pigments in black rice. Foods and Biotechnology 3 : 131-136.

Choi HC et al. 1996. Development nad industrial utilization of natural pigments from colored rices, G7 final report. NCES, RDA.

Dooner HK., TP. Robbins, RA. Jorgensen. 1991, Genetic and developmental control of anthocyanin biosysnthesis. Annu. Rev. Genet. 25 : 173-199.

Fitzgerald MA, SR McCouch, RD Ha. 2009. Not just a grain of rice: the quest for quality. Trend Plant Sci. 14 : 133-139.

Kim HY, SZ Park, SJ Han, SN Ryu. 2000. Variation of Cyanidin 3-Glucoside Content in $\mathrm{F}_{2}$ Population of Pigmented Rice. Kor. J. Breeding 32: 333-337.

Ha KY, YD Kim, HT Shin, JK Lee, TH N, NS Shin, et al. 1998. A Newly Bred Rice Cultivar "Heugnambyeo" Having Blackish Purple-grain, Short Culum and Lodging Tolerance. Kor. J. Breeding 30: 384-384.

Hsjeh SC, TM Chang. 1964. Genic analysis in rice, IV. Genes for purple pericarp and other characters. Jap. J. Breeding 14: 1-9.

Jung KH, HJ Koh, JH Lee, SJ Yang, HP Moon, HC Choi. 2000. Visual selection of blackish-purple rices in a segregating population. Kor. J. Breeding 32: 127-131.

Kang MY, YH. Choi, SH Nam. 1996, Inhibitory Mechanism of Colored Rice Bran Extract Against Mutagenicity Induced by Chemical Mutaten Mitomycin C. Agric. Chem. Biotech. 39: 424-249.

Kinoshita T. 1984. Gene analysis and linkage map. In Biology of Rice. JSSP/Elsevier, Tokyo : 187-274.

Kim KH and YP Jeong. 1997. Inheritance of pericarp color of rice grain. Kor. J. Breeding 29: 1-6.

Kim SL, JJ Hwang, J Song, JC Song, KH Jung. 2000, Extraction, Purification and Quantification of Anthocyanins in Colored Rice, Black Soybean and Black Waxy Corn. Kor. J. Breeding 32: 146-152.

Liang J, X Peng, L Yan, S Yafang, S Yun, JS Bao. 2009. Quantitative Trait Loci for Brown Rice Color, Phenolics, Flavonoid Contents, and Antioxidant Capacity in Rice Grain. Cereal Chem. 86: 609-615.

Moon HP, YG Choi, JH Lee, KH Jung, SY Cho, HG Hwang, et al. 1998. A New Early Maturing, Anthocyanin Pigmented Rice Variety "Heugjinjubyeo". Kor. J. Breeding 30: 383-383.

Nagao S. and M. Takahshi. 1956. The third gene in apiculus coloration. Genetic studies on rice plant, XIX. Jpn. J. Bot. 


\section{5: 141-151.}

Koh HJ., YJ Won, GW Cha, MH Heu. 1996. Varietal Variation of Pigmentation and Some Nutrive Characteristics in Colored Rices. Kor. J. Crop Sci. 41: 600-607.

Kwon SW, SH Chu, SJ Han, SN Ryu. 2011. A New Rice Variety 'Superjami' with High Content of cyanidin 3-glucoside. Kor. J. Breeding 43: 196-2000.

Nagai I, G Suzushino, Y Tsuboki. 1960. Anthoxanthins and anthocyanins in Oryzaceae, I. Jap. J. Breeding 10: 47-56.

Osawa T. 1995. Antioxidative defense systems present in higher plants and chemistry and function of antioxidative components. Food \& Food Ingredients J. of Jpn. 163: 19-29.

Park SZ, HY Kim, SJ Han, SN Ryu. 2000. Cyanidin 3-glucoside Content in $\mathrm{F}_{1}, \mathrm{~F}_{2}$ and $\mathrm{F}_{3}$ Grain of Pigmented Rice Heugjinjubyeo Crosses. Kor. J. Breeding 32: 285-290.

Park SZ, JH Lee, SJ Han, HY Kim, SN Ryu. 1998. Quantitative analysis and varietal difference of cyanidin 3-glucoside in pigmented rice. Kor. J. Crop Sci. 43: 179-183.

Reddy VS. KV Goud, R Sharma, AR Reddy. 1994. Ultraviolet-B-responsive anthocyanin production in a rice cultivar in associated with a specific phase of phenylalanine ammonialyase biosynthesis, Plant Physiol.
105: 1059-1066.

Reddy VS, S Dash, AR Reddy. 1995. Anthocyanin pathway in rice (Oryza sativa L.); Identification of a mutant showing dominant inhibition of anthocyanins in leaf and accumulation of proanthocyanidins in pericarp. Theor. Appl. Genet. 91: 301-302.

Rieseberg, LH, MA Archer, RK Wayne. 1999. Transgressive segregation, adaptation and speciation. Heredity 83: 363-372.

Ryu SN, SZ Park, CT Ho. 1998. High performance liquid chromatographic determination of anthocyanin pigments in some varieties of black rice. Journal of Food and Drug Analysis 6: 729-736.

Ryu SN. 2000. Recent process and future of research on anthocyanin in crops I . Rice, Barley, Wheat, Maize and legumes. Kor. J. Intl. Agri. 12: 41-53.

Shen Y, L Jin, P Xiao, Y Lu, JS Bao. 2009. Total phenolics, flavonoids, antioxidant capacity in rice grain and their relations to grain color, size and weight. J. Cereal Sci. 49: 106-111.

Yoshimura A, O Ideta, N Iwata. 1997. Linkage map of phenotype and RFLP markers in rice. Plant Mol. Biol. 35: 49-60. 